East African Medical Journal Vol. 78 No. 1 January 2001

SCHISTOMIASIS OF THE SPINAL CORD: REPORT OF TWO CASES

G. Owor, MBChB, Medical Officer, Conultant, Makerere Univerity Medical School; A. Korolev, MD, PhD, Consultant Neurosurgeon; H. Ssenyonjo, MBChB, Medical

Officer and J. Kiryabwire, MBChB, MMed, Surgeon, Makerere University Medical School, Mulago Hospital, P.O. Box 7072, Kampala, Uganda

Request for reprints to: Dr. G. Owor, Makerere University Medical School, P.O.Box 7072, Kampala, Uganda.

\title{
SCHISTOMIASIS OF THE SPINAL CORD: REPORT TWO CASES
}

\author{
G. OWOR, A. KOROLEV, H. SSENYONJO and J. KIRYABWIRE
}

\begin{abstract}
SUMMARY
Schistosomiasis affects over 200 million people worldwide. Schistosomiasis of the spinal cord is a rare occurrence. In Africa, there have been recent reports from Egypt and South Africa. In Uganda, the last histological records were over two decades ago. Schistosomiasis of the spinal cord is commonly caused by Schistosoma mansoni although Schistosoma haematobium has been isolated. Two case reports are presented. In both patients, the diagnosis was made retrospectively. The first patient was a female patient with a lesion in the thoracic region. The second patient was a 21 year old male with a lesion in the conus. Apart from a block on the myelograms, all other laboratory investigations were negative. The diagnosis was made histologically in both cases with the identification of eggs of schistosoma in the spinal cord. The eggs could however, not be retrieved from the stool or urine samples. Both patients were treated with antischistosomal drugs and steroids. On follow up they had marked improvement in their neurological signs. We hope to renew attention in this rare but devastating neurological manifestation of a disease which affects many in our region and which if left untreated can lead to permanent neurological damage.
\end{abstract}

\section{INTRODUCTION}

Schistosomiasis affects over 200 million people worldwide(1) Schistosomiasis of the spinal cord is a rare occurrence (2-4). Since 1953 there have been over 40 case reports of schistosomiasis of the spinal cord reported. In Africa, there have been three recent reports from Egypt and five from South Africa. In East and Central Africa, reports have been scanty and were published over a decade ago $(6,7)$.

Schistosomiasis of the spinal cord is commonly caused by Schistosoma mansoni(3) although Schistosoma haematobium has been isolated(3,5). The pathology of schistosomiasis of the central nervous system is well known(1). Cohen et al(8) found the commonest site in the spinal cord to be the conus medullaris. Early intervention has been found to lead to good neurological recovery $(3,9,10)$

\section{CASE REPORTS}

Two patients who presented to the Neurosurgical Department in 1998 and 1999 are reported. The diagnosis of schistosomiasis of the spinal cord was made retrospectively in both cases.

Case 1: Patient $A$ was a young 18 year old female who was referred from a rural hospital in western Uganda with a history of gradual onset of weakness of the lower limbs, back pain, as well as urinary incontinence developing over 11 weeks. She had a history of dysuria which was being treated as a pelvic inflammatory disease. Clinically she had spastic paraplegia of the lower limbs (Grade 0) with a sensory level at thoracic spine 12 (T12) and localised spinal tenderness at thoracic spine 9 (T9).
She was investigated with a full haemogram, thoracolumbar radiographs, CT myelograms and lumbar puncture. The myelogram showed a block at T9 (Figures 1 and 2). The bones appeared normal. At laminectomy a soft intra medullary mass was found. The histology results showed eggs of Schistosoma haematobium and myelitis. A urinalysis and stool analysis were performed and the patient started on praziquantel and high dose dexamethasone. Urinalysis and stool results did not yield any ova or cysts. One year later she had normal muscle power and sensation.

Figure 1

Plain myelogram of patient A with a block at thoracic spine 9 (T9) (indicated by sudden absence of contrast beneath vertebra pointed at by arrow) The bones appear normal

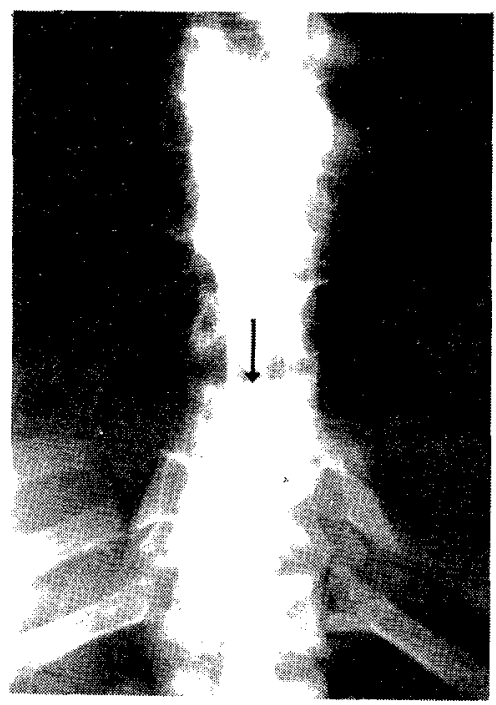


Figure 2

Lateral view of myelogram of patient A showing the block at thoracic spine $9(T 9)$ indicated with an arrow



Case 2: Patient B was a 21 year old male from Masaka in central Uganda who while performing a dance on stage fell down hitting his back. He felt some slight back pain but was able to get up and walk. One week laterhe developed gradual and progressive loss of sensation in the lower limbs which was followed by weakness and incontinence of urine. Four weeks later he presented to the Neurosurgical unit where $x$-rays of the Spine and a myelogram were performed. The myelogram showed a block at $\mathrm{T12}$, the $\mathrm{X}$-rays were normal. He had flaccid paraplegia and saddle anaesthesia with a sensory level at L2 . At laminectomy a tumour like mass involving the cauda equina and the nerve roots was found. Biopsy results showed schistosomal eggs with necrotic myelitis (Figure3). Urinalysis and stool analysis were negative for schistosomal eggs or cysts.

Figure 3

Histology specimen of patient $B$ showing schistosomal granuloma centre of field

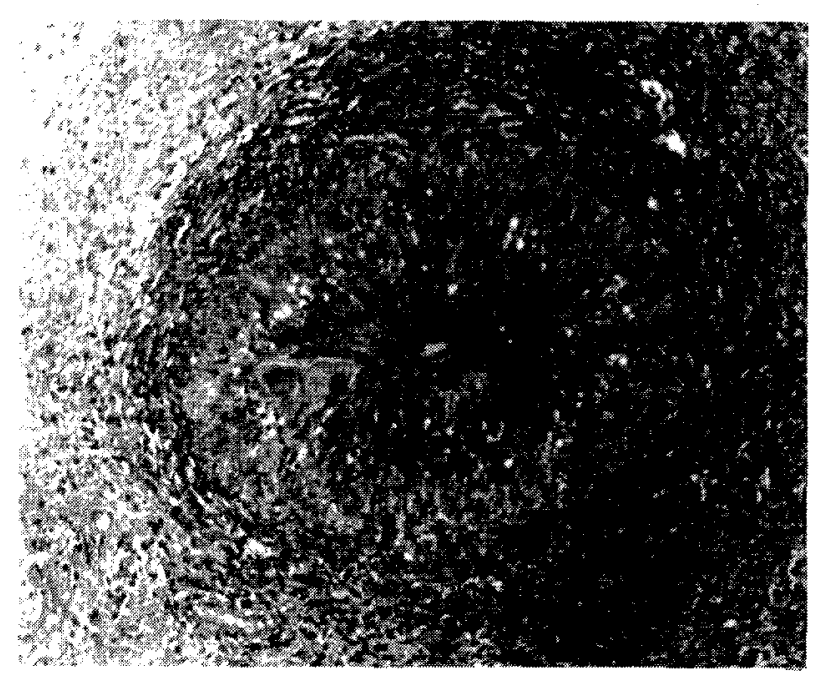

The patient was started on praziquantel with high dose dexamethasone and discharged. Follow up at six months revealed recovery of muscle power to Grade 3 and sensory level to T12

\section{DISCUSSION}

Patient $B$ was from central Uganda which is not traditionally a schistomiasis endemic area(11). However, the rest of the presentation was classical $(3,9)$. Patient A was less typical. She had a lesion in the thoracic spine and Schistosoma haematobium was identified as the cause where as most patients are found to have Schistosoma mansoni( 2,5$)$. In both patients the diagnosis was not suspected preoperatively. A study in Natal, South Africa noted that patients who were operated had a clear diagnosis whereas those with myelitis were easily missed(5). Eosinophilia which has been noted in many patients $(10,12)$ was not present in our patients. Peregrino et al (10) have proposed a clinical and laboratory investigation protocol for the diagnosis of schistosomiasis of the spinal cord without a histological diagnosis. This approach may be useful in a patient without mass effects on the spine. Other studies have reported typical lesions on MRI $(2,8)$. However, in a setting with limited facilities, a histological diagnosis of the spinal lesion is often the best option for patients with mass effects and a high index of suspicion should be maintained for patients without mass effects.

The pharmacological treatment of the patients using antischistosomal drugs and steroids is recommended; as well as surgical decompression of tumour-like lesions $(9,13,14)$. However, randomised controlled trials comparing operative and drug treatment have not been performed. No consistent pattern of response to any single treatment modality has been found(15) but it is clear that early treatment leads to subsequent improvement of neurological signs $(2,13)$. We hope that through this report we can renew the interest of physicians in this rare condition which, if not diagnosed, in time can lead to devastating effects.

\section{REFERENCES}

1. Pittella, J.E. Neuroschistosomiasis. Brain Pathol. 1997; 7:649-62

2. Bennett, G. and Provenzale, J.M. Schistosomal myelitis: findings at MR Imaging; Eur. J. Radiol. 1998; 27:268-70

3. Elkhayat, R.A. and Girgis, M. Bilharzial Granuloma of the Conus; case report. Neurosurgery. 1993; 32:1022-4.

4. Queiroz, L.S., Nucci, A., Facure, N.O. and Facure, J.J. Massive Spinal Cord Necrosis in Schistosomiasis: Arch Neurol 1979; 36:517-9.

5. Cosnett, J.E. and Van Dellen, J.R. Schistosomiasis (Bilharzia) of the Spinal Cord: case reports and clinical profile. Quart. J. Med. 1986; 61:1131-9

6. Abbot, P.H. and Spencer, H. Transverse myelitis due to ova of Schistosoma mansoni. Trans. roy. Soc. trop. med. Hyg. 1953; 47:221.

7. Owor,.R. and Madda, J.P. Schistosomiasis causing tumour like lesions . East Afr. Med. J. 1977; 54.

8. Cohen, J., Capildeo, R., Rose, F.C. and Pallis, C. Schistosomiasis of the Spinal cord. Contribution of magnetic resonance imaging. Brit. Med. J. 1977; 14:1258 
9. Ueki, K., Parisi, J.E. and Onofrio, B.M. Schistosoma mansoni infection involving the spinal cord. J. Neurosurg. 1995;82:10657

10. Peregrino, A.J., de Oliveria, S.P, Porto, C.A., Santos, L.A., de Menezes, E.E., Silvia, A.P., Brito, A.L, Pinheiro, S.P., Pinnheiro, S. and Dias, A.B . Meningomyeloradiculitis caused by Schistosoma mansoni. Research Protocoi and report of 21 cases. ArqNeuropsiquiatr. 1988; 46:49-60.

11. Ongom, V.L. and Bradley, D.J. The Epidemiology and consequences of Schistosoma mansoni infection in West Nile, Uganda.I. Field Studies of a community at Panyagoro. Trans. roy. Soc.trop. Med. Hyg. 1972; 66:835.
12. Loutan, L., Farinelli, T. and Robert, C.F. Acute Schistosomiasis or Katayama Syndrome; apropos of 2 mini epidemics. SchweizMed-Wocchenschr. 1996; 126:1482-6.

13. Lechtenberg, R. and Vaida, G.A. Schistosomiasis of the Spinal Cord. Neurology. 1977; 27:55-9.

14. Nazer, H., Hugusson, C. and Posas, H. Transverse myelitis in a child with Down's Syndrome and schistosomal colitis. Ann Trop-Paediatr. 1993; 13:353-7.

15. Andrade, Filho-AA-de-S, Reis, M.G., de Souza-A.L., Martins, E.R. et. al. Mansonic neuroschistosomiasis: clinical, laboratory and therapeutic aspects. Arg Neuropsiquitar. 1996; 54:232-7.

\section{SOCIETY OF NEUROSCIENTISTS OF AFRICA (SONA)}

and

INTERNATIONAL CHILD NEUROLOGY ASSOCIATION (ICNA)

in conjuction with

KENYA PAEDIATRIC ASSOCIATION (KPA)

and

NEUROLOGICAL SOCIETY OF KENYA (NSK)

announce

\section{A Symposium on Child Neurology and Development Medicine in Africa}

Venue: The Safari Park Hotel, Nairobi, Kenya

Dates: 27th - 29th April 2001

Contact Person:

Mrs. Veronica Wambugu

Organising Secretary

Wellcome Trust Research Laboratories

P.O. Box 43640, Nairobi, Kenya,

Tel: (254-2-710672/715160/711673

Fax: (254-2-711673

e-mail: veronica@wtrl.or.ke 